\title{
Energy efficiency in the context of energy availability in the Republic of Tajikistan
}

\author{
M. Halimjanova ${ }^{1}$, D. Schulz ${ }^{1}$, K.-D. Dettmann ${ }^{1}$ \& A. Akhrorova ${ }^{2}$ \\ ${ }^{1}$ Helmut-Schmidt-University, \\ University of the Federal Armed Forces, Germany \\ ${ }^{2}$ Tajik Technical University, Tajikistan
}

\begin{abstract}
According to system indicators characterizing low usage efficiency of fuel and energy resources and the level of energy availability in Tajikistan, the main challenge to the electrical power production in the country is losses of electrical energy at the stages of production, transmission, distribution and use. This problem is a peculiar issue that has gained special awareness in recent years, also considering the withdrawal of effective power transits between central Asian countries like Tajikistan, which is of particular importance during autumn and winter periods.

Keywords: Tajik Aluminium Company (TALCO), energy security, transmission lines, harmonics, thyristor convertor, filter-devices, Central Asia and South Asia project (CASA-1000), thermoelectric plant (CHP), hydro power plant (HPP), DIgSILENT PowerFactory 2016.
\end{abstract}

\section{Introduction}

This paper analyzes the losses of electrical energy at the Pryadilnaya substation with $220 / 110 / 10 \mathrm{kV}$ and the $220 \mathrm{kV}$ transmission line as well as the undesirable effects of harmonics $(5,7,11,23$ order) on the high voltage line. These harmonics cause disturbances or distortion in the electrical network, with different manifestations such as pulses, phase imbalance, throws and dips, which are categorized as transient disturbances. 


\section{Problem description}

Providing and supporting a stable energy availability in a country is one of the most important factors of sustainable economic development. Moreover, efficient energy generation provides suitable social and environmental conditions for the population, which also serves as one of the indicators of an efficiently integrated national energy management system. The main direct threats to the energy availability are:

- $\quad$ shortage and low quality of fuel and energy resources;

- $\quad$ interruptions of stable power supply or low reliability of power supply;

- inefficient use of energy resources;

- inadequate supply of energy to consumers due to inefficient utilization of local fuel and energy resources.

In the last decade, these energy problems became a paramount issue after the loss of effective energy relations among the countries of Central Asia in 2009. Since 2010, Tajikistan can't export electricity to Kazakhstan and southern Russia, because Tajikistan's electrical power system was connected with these countries through the energy system of Uzbekistan. The effect of these electrical power supply problems in Tajikistan is further aggravated in the autumn-winter period. Tajikistan can't import electricity during the winter when there is an acute shortage of energy in the country. On the other hand, Tajikistan can't export electricity in large quantities in the summer when the power system of Tajikistan could generate electricity in an amount exceeding the country's own demand. Surplus electricity in the summertime can reach up to $7000 \mathrm{GWh}$ but, because of the lack of a market, this electricity can't be generated. The annual financial losses sum up to an amount of about $\$ 200$ million [6]. In addition, $93.9 \%$ of the energy generated in Tajikistan is produced by hydroelectric power stations (see Figure 1).

Production capacities are severely hampered during the winter period due to the reduction of water flow from the river. This culminates in the inability of the power system to meet the required energy demand when the load (energy consumption) increases. For this reason, the electrical energy problems in Tajikistan require special attention. However, an adequate solution to these energy problems not only resides in improving the technologies used during the production and distribution phases but also in encouraging a good consumer's energy consumption culture in the country at large. The reasons behind the escalating increase of electrical energy losses are as follows:

- Overloaded transformers. For example, substation Pryadilnaya $220 / 110 / 10 \mathrm{kV}$ has two different transformers (T1-63 MVA, overloaded with 315\%, T2-125 MVA, underutilized with 84.3\%) (see Figure 2). In this situation we will get really fast subsequent problems:

1. the output voltage drops, making it much more difficult for hard starting devices [2];

2. the generation of heat is quadratic with $I^{2} R$. If the transformer is overloaded by $130 \%$, the heat increase is $70 \%$ [2]. 


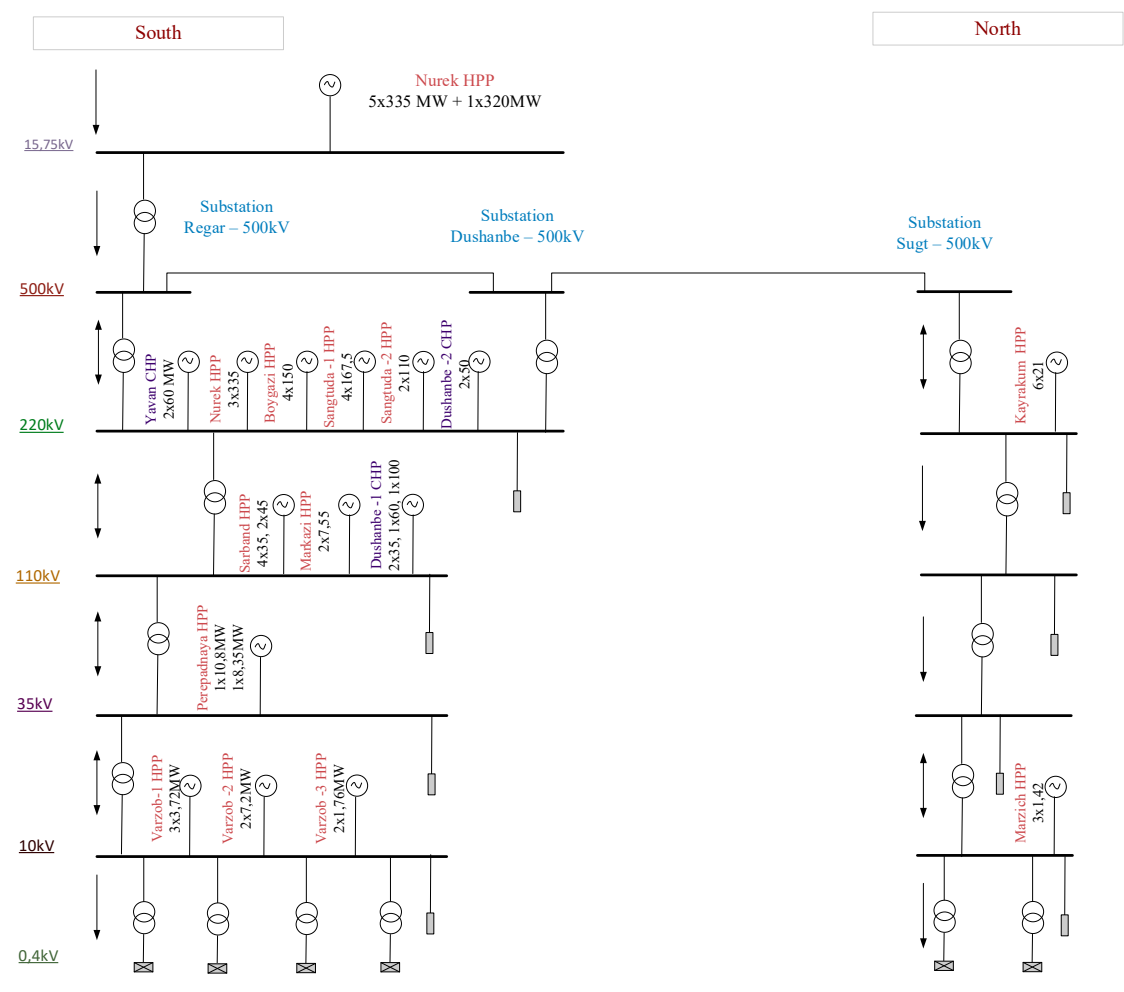

Figure 1: Principle scheme of power transmission lines, existing HPP and voltage levels in Tajik power grid.

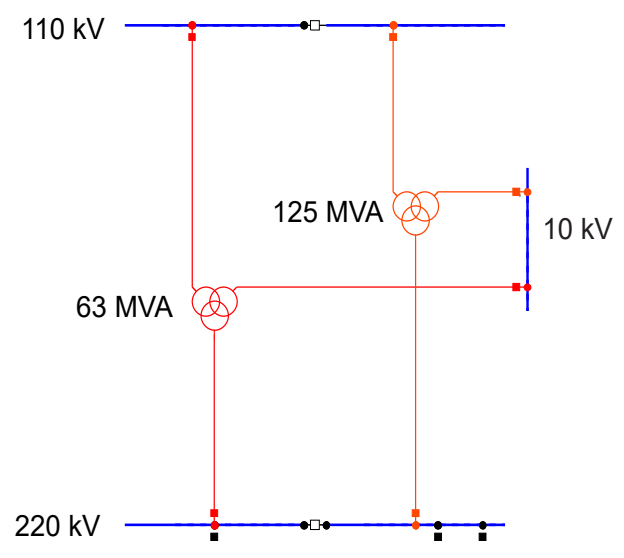

Figure 2: Substation Pryadilnaya $-220 / 110 / 10 \mathrm{kV}$ has two different transformers (T1-63 MVA, overloaded with 315\%, T2-125 MVA, underutilized with $84.3 \%$ ). 
- Underutilized transformers - result: magnetization losses on idling (see Figure 3);

- Overloaded power lines, for example on the $220 \mathrm{kV}$ voltage line connecting substation Sebiston with HPP Norak we have 118\%;

- The absence or insufficient use of voltage control and reactive power compensation - result: reduced quality of electrical power;

- Unbalanced load on the consumer substation - result: high currents in the neutral conductor;

- "Commercial losses" - losses due to unauthorized, illegal connection to the public electricity grid;

- The constant increase in non-linear consumers such as uninterruptible power supplies (UPS), convertors, thyristor systems, diode bridges, melting furnaces of high frequency, computers, etc., is the cause of the higher harmonics experienced in the power network, which in turn increases the power losses in the grid. In addition, 35\% of electricity consumed are converted to constant voltage [1].

- Low power factor $(\cos \varphi)$ on power lines.

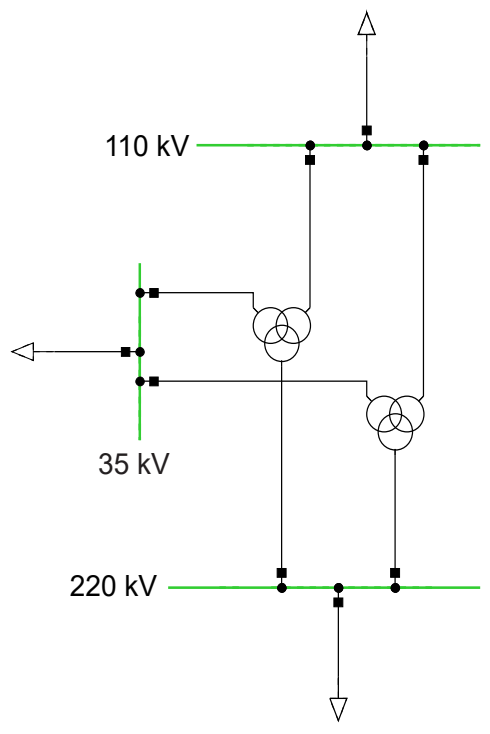

Figure 3: Substation Kolchozobod 220/110/35 kV (both transformers 63 MVA, both underutilized with $50.9 \%$ ). 
The Tajik electrical power system has all these problems and it is very important to consider all these options in order to reduce electricity losses in all production stages.

Prime costs of the electricity in power plants is always an important issue. Figure 4 shows real prime costs of electricity in the Republic of Tajikistan during several years for different power plants. For example, HPP Kayrakum has installed a capacity of $126 \mathrm{MW}$; the prime costs in 2009 in this station were 0.17 cents $/ \mathrm{kWh}$. In Dushanbe CHP-1 with a capacity of 120 MW the prime costs in 2009 were 9.79 cents $/ \mathrm{kWh}$. These results show that the prime costs of electricity in HPP are 50 times cheaper than the prime costs of CHP.

The differences between the power plants depend on their types and capacities. For example, producing electrical energy in a thermoelectric plant (CHP) is more expensive than in a hydropower plant (HPP). Furthermore, producing electricity by big HPP is more efficient than producing by small HPP.

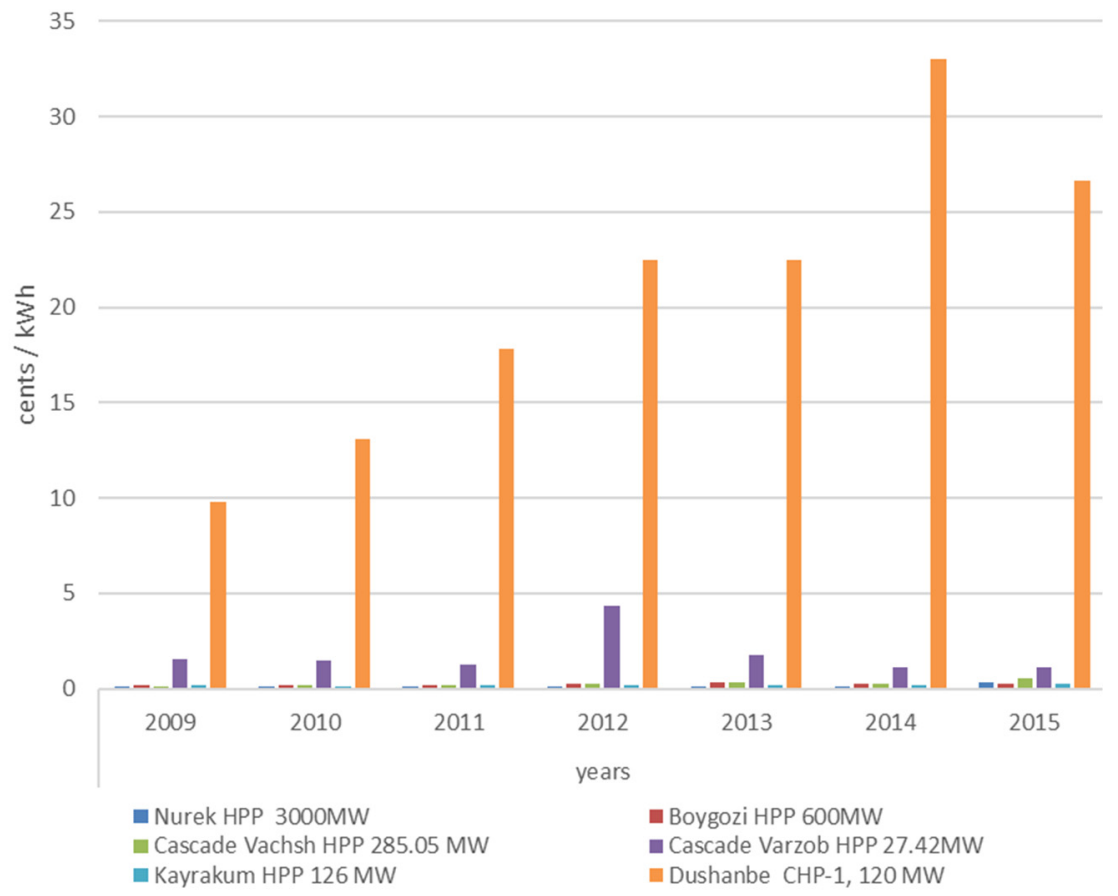

Figure 4: Prime costs of production, transmission and distribution of electrical and thermal energy in Tajik power plants [5]. 


\section{Proposed solution}

Figure 2 shows one substation (Pryadilnaya) in Tajikistan. This illustration was exerted with the help of the software DigSILENT PowerFactory 2016. We can see that in the substation there are two power transformers with different load capacities, which lead to the result that the transformers operate in incorrect load ranges, if the substation has full load. As depicted in the figure, the left of the two transformers at the substation has a capacity of 63 MVA, which is overloaded with $315 \%$. On the contrary, the transformer on the right-hand side has a capacity of $125 \mathrm{MVA}$ and is underutilized by $84.3 \%$. For an effective operation of the electric power system, it is vital that the transformers must have approximately the same load capacities.

On one substation only transformers with the same technical parameters may be installed, because failures of the equipment become more probable, if overload conditions occur. Figure 3 shows an example of a correct installation. It represents the substation Kolchozobod $(220 / 110 / 35 \mathrm{kV})$ established in Tajikistan, which has two transformers with the same parameters. Therefore, both transformers would work with normal load conditions, if the substation had a full load. However, the total load of this substation is only $50.9 \%$. So the transformers are underutilized, but both with the same load.

As shown in Figure 5, there are always differences between electricity generation and demand in the country. These differences originate from the losses of electrical energy in Tajikistan (technical losses + commercial losses) and the insufficient energy production in wintertime due to one of the problems highlighted in section 2. The Energy Company has to purchase the missing electrical energy from neighbouring countries annually (especially during the wintertime) to meet the surging demands of consumers.

In Tajikistan the largest consumers of electricity are the industrial enterprises, which consume more than $48.38 \%$ of the total amount of electricity produced. The second largest consumer is the public - with almost $28.92 \%$, followed by the irrigation pumping stations with almost $19.6 \%$ consumption rate, lastly followed by the communal enterprises and electric transport with $3.1 \%$ (not taking into account the limitations experienced during the winter) [1].

For example, Tajik Aluminium Company (TALCO), which provides more than $75 \%$ of foreign exchange earnings in the country's economy, could use up to $20 \mathrm{GWh}$ per day. However, TALCO uses a thyristor convertor installation, which in turn is a powerful source of harmonics $(5,7,11,23$ order). Power thyristor convertors are about $80 \%$ of the electrical load of TALCO. It should be noted that almost all transformer points are connected to converting installations, which are sources of various harmonics.

One of the most effective actions to reduce the influence of inverters on the power grid, thus improving the quality of the voltage, can be the use of power resonant L-C-filters in $6-10 \mathrm{kV}$ grids of industrial enterprises. The filters must be tuned to the frequencies of the harmonic amplitude spectra and connected in parallel to the loads. The absence of filter-devices at substations leads to negative consequences, some of which include: 
- Failure of the units for electrical power consumption. They are not designed for the flow of currents with higher harmonics. This results in operation with low power factor in these enterprises.

- Reduced effectiveness of the processes of generation, transmission and use of electrical power.

- Reduced service life of electrical equipment.

- Violation of relay protection and automation networks.

mln. kWh

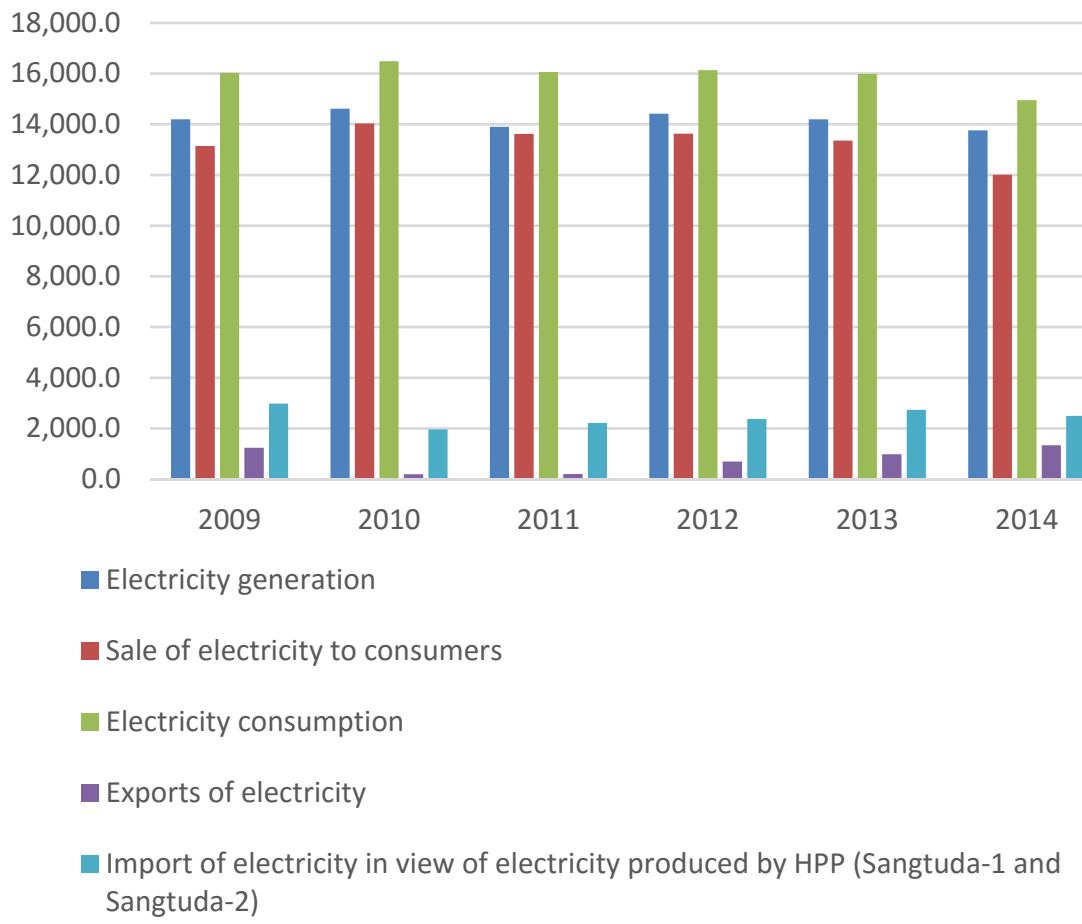

Figure 5: Production indicators of the power system of the Republic of Tajikistan.

For improving the actual situation in Central Asia and South Asia a new project CASA-1000 has been started. This project has the goal to create a good solution for the problems with the summer electricity surplus. At first, a new AC-DC voltage convertor station will be built. Figure 6 shows an overview of the CASA1000 project. 


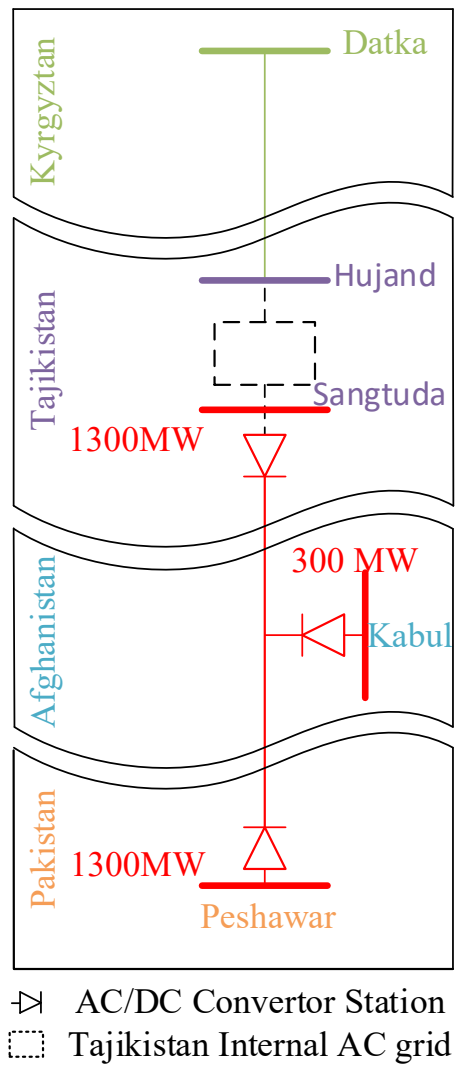

Figure 6: $\quad$ Project CASA-1000 [7].

In summertime, the two countries (Tajikistan, Kyrgyzstan) have a surplus of electrical energy close to $6000 \mathrm{GWh}$, which will be exported to neighbouring countries (Afghanistan, Pakistan) in the future. This energy production should be reduced to less than $900 \mathrm{GWh}$ by 2035 .

The CASA-1000 project will include:

- $\quad 500 \mathrm{kV}$ AC line from Datka (Kyrgyzstan) to Hujand (Tajikistan) with a total length of $477 \mathrm{~km}$;

- 1300 MW AC-DC Convertor Station at Sangtuda (Tajikistan);

- High-voltage DC line from Sangtuda to Kabul (Afghanistan) to Peshawar (Pakistan) with a total length of $750 \mathrm{~km}$;

- $300 \mathrm{MW}$ Convertor Station at Kabul for energy export;

- 1300 MW DC-AC Convertor Station at Peshawar [7]. 
This project will be realized in cooperation with four countries (Kyrgyzstan, Tajikistan, Pakistan, Afghanistan). All these countries will be connected with high voltage transmission lines. This project gives the possibility of exporting a summer surplus of 1000-1300 MW from Central Asia (Kyrgyzstan, Tajikistan) to South Asia (Pakistan, Afghanistan). The project can be completed within a minimum of 58 months. This completion period, however, could be delayed twelve months, depending on different factors.

\section{Conclusion}

For the Republic of Tajikistan, where the deficiency of energy is big, it is necessary to maximize the sales of all produced electrical power and to minimize the technical losses. Simulations of the Tajik grid have identified overloaded as well as underutilized transformers in substation "Pryadilnaya" $(220 / 110 / 10 \mathrm{kV})$ and showed problems that actually exist in the Tajik energy system. All calculations are based upon real data and are performed by DIgSILENT PowerFactory 2016.

We recommend the improvement of the power supply system with a focus on the $220 \mathrm{kV}$ level and on industrial enterprises grids.

\section{References}

[1] Andrew Lantsov. Quality parameters of electricity, accessed 02.06.2016, http://e-audit.ru/quality/no_sinus.shtml

[2] Overloads - Application Notes from 22 April 1988, Controlled Power Company, accessed 02.06.2016, http://www.controlledpwr.com/whitepapers/ ukloada1.pdf

[3] Roger C. Dugan, Mark F. McGranaghan, Surya Santose, H. Wayne Beaty. Electrical Power Systems Quality, Second Edition: Publishing Copyrighted Material, pp. 20-25 2004

[4] Janybek O, Thomas L. Diagnostic Study ratio demand / supply of electricity and infrastructure constraints RETA-6488: CAREC action plan in the energy sector 2010, Publishing The Asian Development Bank, 2010, accessed 02.06.2016, http://www.carecprogram.org/uploads/docs/Foundation-Studies/ Diagnostic-Study-CAREC-Energy-Strategy-Pillar1-Full-Report-ru.pdf

[5] Compiled 2016 from materials of the Ministry of Energy and Industry of the Republic of Tajikistan.

[6] Kazakhstan Today - Tajikistan has started to produce idle discharges from the Nurek reservoir due to the inability to export electricity, accessed 02.06.2016, http://kt.kz/rus/economy/tadzhikistan_pristupil_k_holostomu_ sbrosu_s_nurekskogo_vodohranilishta_izza_nevozmozhnosti_eksporta_elek troenergii_1153591470.html

[7] CASA-1000, project duration 2015-2020, accessed 02.06.2016, http://www.casa-1000.org/ 